\title{
REFERENCIAS HISPÁNICAS A ZOLA Y A LA MEDICINA EXPERIMENTAL EN 1868
}

\author{
XAVIER VALL \\ Universitat Autònoma de Barcelona
}

\section{RESUMEN}

Retrotrayendo la fecha del impacto hispánico de Zola, se aportan comentarios sobre Thérèse Raquin del corresponsal parisino del Diario de Reus (muy probablemente, Ángel Vallejo Miranda) y una mención como redactor de La Tribune por Josep Coroleu en el diario barcelonés $E l$ Principado. Mientras que el uno, coincidiendo con Louis Ulbach, censura el carácter depravado y médico de diversas novelas (entre ellas también La comtesse de Châlis, de Ernest-Aimé Feydeau), el otro defiende el realismo de esta obra y, citando Claude Bernard, el método experimental. Aunque el naturalismo zoliano todavía tenía que desarrollarse, estos textos manifiestan ya dos actitudes opuestas, que adquirirán una amplia gama de matices.

Palabras clave: realismo, naturalismo, materialismo, positivismo, determinismo, medicina experimental, Émile Zola, Claude Bernard, Ángel Vallejo Miranda, Josep Coroleu Inglada.

\section{HISPANIC REFERENCES TO ZOLA AND EXPERIMENTAL MEDICINE IN 1868}

\begin{abstract}
Putting forward the date of Zola's Hispanic impact, this article provides comments about Thérèse Raquin by the Diario de Reus' correspondent in Paris (very likely, Angel Vallejo Miranda) and a mention as an editor of La Tribune by Josep Coroleu in El Principado, of Barcelona. While one, coinciding with Louis Ulbach, censures the depraved and medical character of various novels (such as also La Comtesse de Châlis, by Ernest-Aimé Feydeau), the other defends the realism of this work and, quoting Claude Bernard, the experimental method. Although Zola's naturalism had yet to develop, these texts manifest two opposing attitudes, which acquire a wide range of hues.
\end{abstract}

Key words: realism, naturalism, materialism, positivism, determinism, experimental medicine, Émile Zola, Claude Bernard, Ángel Vallejo Miranda, Josep Coroleu Inglada.

\section{INTRODUCCIÓN}

La incidencia hispánica de Zola, más allá del libro de Pattison, que contaba ya con precedentes, ha sido objeto de abundantes estudios e incluso de un 
coloquio monográfico, además de otros relacionados con el tema ${ }^{1}$. Sin embargo, sigue olvidada todavía documentación dispersa. En concreto, se ha reiterado que la referencia más antigua al naturalismo es de 1874 y la primera mención de Zola de $1876^{2}$. En cambio, en 1868 figura ya en la prensa catalana: el corresponsal en París del Diario de Reus (argumentaré que debe tratarse de Ángel Vallejo Miranda) critica Thérèse Raquin y, en el periódico barcelonés El Principado, Josep Coroleu enumera Zola entre los redactores de La Tribune.

Estos artículos son una muestra de las abundantes relaciones hispanofrancesas, con la intermediación destacada de la colonia hispánica de París, que por aquel entonces se estimaba en 2.536 personas $^{3}$. Los entroncaré con otras crónicas y los contextualizaré en las actitudes de sus autores hacia el naturalismo, el cual, al igual que su incidencia, se enmarca en la proyección social de la medicina (en especial, con el higienismo) y en su variada presencia literaria y en la propagación del materialismo, del positivismo y del método experimental de Claude Bernard ${ }^{4}$.

${ }^{1}$ PATTISON, T. Walter. El naturalismo español. Historia externa de un movimiento literario. Madrid: Gredos, 1965, reeimpreso en 1969; Zola y España. Actas del Coloquio Internacional. Lyon (septiembre, 1996). Simone Saillard y Aldofo Sotelo Vázquez (eds.). Barcelona: UB, 1997. Entre otros repertorios o balances bibliográficos específicos, véanse LAFARGA, Francisco. Bibliografía anotada de estudios sobre recepción de la cultura francesa en España (siglos XVI-XX). Barcelona: PPU, 1998; BARRERO PÉREZ, Óscar. «Revisión crítica del naturalismo. Actualización de un debate histórico». Anuario de Estudios Filológicos, 1999, vol. XXII, pp. 55-71; RUBIO CREMADES, Enrique. Panorama crítico de la novela realista-naturalista española. Madrid: Castalia, 2001. Me limitaré a mencionar solamente los trabajos más relacionados con mi artículo, que se inscribe en los proyectos HUM 2006-07206-C03-01 y HAR2009-12918-C03-02.

${ }^{2}$ Aunque esta cronología figura en numerosos estudios, sobre los inicios de la penetración del naturalismo, véanse, en particular, DAVIS, Gifford. «The Critical Reception of Naturalism in Spain before La cuestión palpitante». Hispanic Review, abril 1954, vol. XXII, $\mathrm{n}^{\circ}$ 2, pp. 97-108; ALAOUI, Setty. «Sur quelques aspectes de la première réception des œuvres d'Émile Zola et du naturalisme en Espagne (1874-1880)». Textures, 1995, $\mathrm{n}^{\circ}$ 1, pp. 43-55, e id. "Zola en Espagne: horizon d'attente et réception». Excavatio, 2003, vol. XVIII, $\mathrm{n}^{\text {os }} 1$ 2, pp. 179-197. Se ha aducido también la crítica al «naturalismo realista y grosero, punto menos que tabernario» del lenguaje novelístico, como «carácter» pretendidamente «español», por Ventura Ruiz Aguilera en Proverbios ejemplares, serie I, Madrid: Leocadio López, 1864, pp. V-VI, pero situándolo «sixteen years before the first direct impact of naturalism was experienced in Spain» (RODGERS, Eamonn. «The reception of Naturalism in Spain». En: Naturalism in the European Novel. New Critical Perspectives. Brian Nelson (ed.). New York / Oxford: Berg, 1992, p. 124). Solange Hibbs-Lissorgues ha anunciado un estudio sobre «El polémico debate del naturalismo en la prensa católica del siglo XIX (1870-1890)», pero ha tenido la amabilidad de aclararme que, al igual que en otros trabajos suyos sobre el tema, no se aportan referencias al naturalismo zoliano anteriores a las conocidas.

3 «Revista de París», 9 de marzo. El Imparcial, 13-3-1868, año II, no 315, s. p., y, con la misma fecha y firmada «Ángel Jo-valle». Diario de Reus, 14-3-1868, año X, no 61 [n 62], pp. 1-2.

${ }^{4}$ Se dispone de bastante bibliografía sobre estos temas. Carlos Mendoza, en La Ilustración Ibérica, 13-8-1887, año $\mathrm{V}, \mathrm{n}^{\circ} 241$, p. 527, quejándose ya de que se olvidasen las apor- 
Aunque se ha matizado su influencia en Zola, se ha conjeturado que este leyó su Introduction à la médicine expérimentale (1865) «peut-être» «dès sa publication, dont il a très certainement entendu parler alors — les chroniques scientifiques étant nombreuses dans les journaux qu'il lisait assidûment—», $\mathrm{y}$, con toda seguridad, para su «célèbre article «Le roman expérimental» (paru dans Le Messager de l'Europe en septembre 1879 et repris dans le recueil du même nom en 1880)» ${ }^{5}$. En cualquier caso, formaba parte ya del contexto científico de la época de Thérèse Raquin.

Tras las versiones publicadas en Le Figaro (el 24 de diciembre de 1866) y en L'Artiste (de agosto a octubre de 1867, en tres entregas), el libro apareció en noviembre de aquel año ${ }^{6}$. «Euvre cohérente fortement construite, soutenue par une thèse vigoureuse sur la nature humaine, inaugure une nouvelle époque» en la «histoire intellectuelle» de Zola, ya que «transpose une hypothèse scientifique, la physiologie des tempéraments, au plan d'une «expérience» narrative: que se passe-t-il lorsqu'un tempérament nerveux, contraint de partager son corps et sa vie avec un tempérament lymphatique, rencontre un tempérament sanguin?» ${ }^{7}$. A pesar de las reminiscencias de la teoría de los humores, al igual que en algunas de las fuentes contemporáneas aducidas, se ha considerado que pone «les premières pierres d'une vaste construction fon-

taciones anteriores a la Revolución de 1868, recordó que Manuel María de Azofra expuso «el positivismo de Comte» en la Real Academia de Ciencias Exactas, Físicas y Naturales de Madrid, aunque se equivocó de discurso y de fecha (se trata de la contestación al de José Balanzat pronunciada en 1866 y editada aquel mismo año). En «L'escepticisme de Joaquim M. Bartrina a través d'»Epístola»». Professor Joaquim Molas. Memòria, escriptura, història, t. II. Barcelona: Universidad de Barcelona, 2003, p. 1164, di noticia de un artículo de este escritor en que se menciona Comte publicado en el Diario de Reus en 1867. LÓPEZ PIÑERO, J. M. «La obra de Claude Bernard en la España del siglo XIX». Boletín de la Sociedad Española de Historia de la Medicina, 1966, vol. VI, nº 2, p. 32, pondera que, «a partir aproximadamente de 1868», «fue muy frecuente el manejo» de sus libros y artículos, remitiendo a las «numerosas citas de sus obras que aparecen en las publicaciones médicas españolas». Si bien se habían traducido ya al castellano trabajos suyos mucho antes y López Piñero mismo ha aducido en otros estudios algún ejemplo anterior del influjo de Bernard, los que se encuentran en la historiografía de la medicina hispánica, en que se cuenta con algunos estudios monográficos, suelen ser posteriores.

${ }_{5}$ S. v. «Bernard, Claude». En: BECKER, Colette; GOURDIN-SERVENIÈRE, Gina; LAVIELLE, Véronique. Dictionnaire d'Émile Zola. Paris: Robert Lafont, 1993, p. 51. Prolifera la bibliografía sobre la influencia de Bernard en Zola y, más en general, sobre la presencia de la medicina en su obra. En el ámbito hispánico, destaca la tesis de HUERTAS GARCÍA-ALEJO, Rafael. «Medicina y ciencia en el naturalismo literario de Emilio Zola». Madrid: UCM, 1984. Entre otras publicaciones suyas sobre el tema, véase «La «novela experimental» y la ciencia positivista». Llull, 1984, vol. VII, no 13, pp. 28-52.

${ }^{6}$ ZOLA, Émile. «Thérèse Raquin». CEuvres complètes. Henri Mitterand (ed.); Robert Abirached y Henri Guillemin (prol.), t. I y XV. Paris: Cercle du Livre Précieux, 1966 y 1969; MITTERAND, Henri. Zola. I. (1840-1871). [Paris]: Fayard, 1999, pp. 569-572, e id. «Thérèse Raquin au théâtre». Revue des Sciences Humaines, octubre-diciembre 1961, fasc. 104, pp. 490-516.

${ }^{7}$ MITTERAND, H., Zola. I, pp. 572 y 575. 
dée sur l'observation exacte du monde contemporain et les dernières découvertes en physiologie» ${ }^{8}$.

En cuanto a la actividad periodística de Zola y, concretamente, a sus artículos de La Tribune, se ha encarecido, además de su interés en sí, la importancia para su formación como escritor y, en particular, su contribución a la observación social ${ }^{9}$.

\section{El DIARIO DE REUS}

En el siglo XIX, esta ciudad gozaba de una gran actividad económica y cultural ${ }^{10}$.El Diario, mientras que hasta comienzos de 1868 había ido reproduciendo las crónicas parisienses de otros periódicos, como El Principado, La Reforma, de Madrid, o el Moniteur, de París, el 11 de enero publicó una de propia, datada el $6^{11}$. Se trata de una gacetilla política, como otras que tampoco comentaré, pero, al día siguiente, apareció, con la misma fecha y también anónimamente, una revista en que se hacía un desolador balance de la temporada teatral: «100 piezas de escasísimo mérito» y poco éxito, a excepción de las antiguas y de Les sceptiques, de Jean Pierre Félicien Mallefille ${ }^{12}$. Asumirá la autoría de estas crónicas «Á. Jo-valle», firma que se reiterará, con

\footnotetext{
${ }^{8}$ BECKER, Colette. Les apprentissages de Zola. Du poète romantique au romancier naturaliste. 1840-1867. Paris: PUF, 1993, p. 1.

${ }^{9}$ Véanse, en particular, KANES, Martin. «Zola, Pelletan and La Tribune». PMLA, septiembre 1964, vol. LXXIX, no 4, pp. 473-483, y MITTERAND, Henri; SUWALA, Halina. Émile Zola. Journaliste. Bibliographie chronologique et analytique. I (1859-1881). Paris: Les Belles Lettres, 1968.

${ }^{10}$ Entre la abundante bibliografía local, véanse ANGUERA, Pere. La burgesia reformista a Reus en els fets de l'any 1868. Reus: Associació d'Estudis Reusencs, 1980, y Historia general de Reus. Id. (dir.), t. III. Reus: Ajuntament, 2003.

${ }^{11}$ «Correspondencia particular del Diario de Reus». Diario de Reus, 11-1-1868, año X, $\mathrm{n}^{\circ}$ 8, pp. 1-2. En aquel mismo año, el Diario editó también «Cartas parisienses» de Federico de la Vega. José María Pereda, en el prólogo a LA VEGA, Federico de. Mesa revuelta. Colección de artículos de costumbres. París: Rosa y Bouret, 1865, p. XIII, se quejaba de que los artículos del autor habían sido «reproducidos de periódico en periódico» sin su permiso. Fuera o no el caso, en el Diario, se editarán, además, sus Diálogos científicos (1873) entre 1874 y 1875 . Sobre el periódico, véanse GRAS I ELIES, Francesc. El periodismo en Reus, desde 1813 hasta nuestros días (1904). Reus: Centre de Lectura, 1973; GUIX I SUGRANYES, J. M. «Diari de Reus a través dels anys». Diari de Reus, 1-1-1935, nº 1 , pp. 1-2; ARAGONÉS VIDAL, Salvador. La Revolución de Septiembre y el «Diario de Reus». Reus: Asociación de Estudios Reusenses, 1969; ANGUERA, Pere; CABRÉ, Rosa. Ideologia $i$ història dels diaris reusencs en català, Reus: Centre de Lectura, 1979; ANGUERA, P. La burgesia reformista a Reus en els fets de l'any 1868, pp. 155-158; id. «La premsa a Reus». En: id. Del Reus contemporani. Fragments d'història. Reus: Centre de Lectura, 1998, pp. $113-125$.

12 «Revista de la semana». Diario de Reus, 12-1-1868, año X, no 9, pp. 1-2.
} 
las variantes de la sustitución de la inicial por «Ángel», de mayúscula después del guión y de la intercalación de otro entre el nombre y el apellido ${ }^{13}$.

Debe tratarse de Ángel Vallejo, conde de Casa Miranda ${ }^{14}$. El pseudónimo coincide con su nombre y con el primer apellido, tras desplazar la última sílaba de este al inicio de la palabra. Vallejo usó múltiples criptónimos, a menudo de carácter alusivo (como «Ángel [de] Miranda», «Ángel Pico de la Mirándola» $\mathrm{y} \ll \mathrm{A}$. d'Ariman» $)^{15}$. «Ángel Jo-valle» mismo insinúa la identificación:

El Jabón Miranda, del nombre de un escritor tan amigo nuestro que no podemos mirarnos en el espejo sin recordarle y que, como parecerá natural a los que conozcan sus prosa meliflua, esta compuesto con jugo de lirios y lechugas; [...] la pomada [...] Miranda, usando la cual no se tiene pelo de tonto ${ }^{16}$.

Vallejo, residente entonces en París, colaboró en la prensa francesa y fue corresponsal de diversos periódicos hispánicos. Como he ido avanzando, algunas de estas crónicas, entre las que no se encuentran las relativas a Zola, se publicaron anónimamente o firmadas simplemente «Ángel» en El Imparcial, a veces con anterioridad, pero también simultáneamente y, en ocasiones, abreviadas ${ }^{17}$. Además, corroboran la atribución las similitudes de estilo, las

${ }^{13}$ JO-VALLE, Á. «Revista de la semana (De nuestro corresponsal)». 14 de enero. Diario de Reus, 18-1-1868, año $\mathrm{X}, \mathrm{n}^{\circ} 14, \mathrm{p} .1$.

${ }^{14}$ Sobre él, véanse «Excmo. Sr. D. Ángel Vallejo Miranda, secretario general de la Comisión de España en París». La Ilustración Española y Americana, 15-8-1878, año XXII, $\mathrm{n}^{\circ}$ 30, pp. 87 y 89; s. v. «Vallejo Miranda (Ángel)». En: Enciclopedia Universal Ilustrada Europeo-Americana, t. LXVI. Madrid: Espasa-Calpe, 1958, pp. 1094-1095; FIGUEROA, Agustín de. La sociedad española de la Restauración. Madrid: Aspas, 1945, p. 83; id. Epistolario de la Restauración. Cartas a Cánovas y textos de Cánovas. Madrid: Rialp, 1985, pp. 97-118; OSSORIO Y BERNARD, Manuel. Ensayo de un catálogo de periodistas españoles del siglo XIX. Madrid: Ayuntamiento / Hemeroteca Municipal, 2004, p. 467.

${ }^{15}$ El segundo es el más conocido y figura en repertorios como Unos cuantos seudónimos de escritores españoles con sus correspondientes nombres verdaderos. Apuntes recogidos y coleccionados por Maxiriarth [J. E. Hartzenbusch]. 2a ed. Madrid: Sucesores de Rivadeneyra, 1904; ROGERS, P. P.; LAPUENTE, F. A. Diccionario de seudónimos literarios españoles, con algunas iniciales. Madrid: Gredos, 1977. En la primera «Revista de la semana» mencionada, se cita el célebre lema de Pico: De omni re scibile. En cuanto al primero, véase VALLEJO MIRANDA, Ángel. Una comida en Versalles con el conde de Bismarck. Madrid: Las Novedades, 1871, p. 42, en que alega las dificultades que tenían los francófonos para pronunciar su primer apellido, pero usó también este pseudónimo en $E l$ Imparcial. Con el tercero firmó el artículo «Cánovas del Castillo». Gazette des Touristes et des Étrangers, 23-3-1884, año VIII, no 373, p. 1, y lo desenmascaró El Correo el 28-3-1884, según noticia de La Vanguardia, 1-4-1884, año IV, nº 153, p. 2176.

${ }^{16}$ JO-VALLE, Ángel. «Revista de la semana», 17 de marzo. Diario de Reus, 21-3-1868, año $X, n^{\circ} 67$ [n $\left.{ }^{\circ} 68\right]$, pp. 1-2. Se publica también, con la misma fecha, pero anónimamente, con el título de «Revista parisién» y sin este pasaje, en El Imparcial, 21-3-1868, año II, n 322 , s. p.

${ }^{17}$ Cf. ÁNGEL. «Revista de París». Dominical de El Imparcial, 16-2-1868, año II, nº 15, s. p; JO-VALLE, Ángel. «París. Revista de la semana». Diario de Reus, 18-2-1868, año X, $\mathrm{n}^{\circ} 38$ [n $\left.\mathrm{n}^{\circ} 40\right]$, pp. 1-2, fechadas el 13 de febrero; JO-VALLE, Ángel, «Revista de la sema- 
notas aristocráticas, las referencias a Madrid (donde Vallejo, nacido en Aranjuez, se había establecido), su afinidad con la línea ideológica dominante en el Diario, su amistad con el reusense Prim ${ }^{18}$.

Por otra parte, las ideas que Vallejo manifestará sobre Zola son similares. En 1877, a raíz de la polémica suscitada por los discursos de Alarcón y Nocedal en el acto de recepción del primero en la Real Academia Española, en que condenaron el «realismo exagerado y las tendencias materialistas de la literatura francesa contemporánea», reprocha a L'assommoir «el más repugnante cinismo, el realismo llevado a sus últimos límites en la descripción de las escenas más bajas y asquerosas» y considera el «talento» «de primer orden» de su autor «el oropel que cubre una píldora emponzoñada» ${ }^{19}$. En otra crónica, imagina el naturalismo como una de las «diversas ramas» del «tronco» de «los realistas» que «se inclinan con creciente voluptuosidad hacia las ciénagas ${ }^{20}$. Con todo, años después, considerará Le rêve, de Zola, como una «obra maestra», «antítesis sorprendente de la manera consuetudinaria de un talento de primer orden degradado por el abuso del naturalismo» ${ }^{21}$. De todos modos, esta novela fue valorada a menudo, bien fuera elogiosa o críticamente, como una «conversión» del autor ${ }^{22}$.

Curiosamente, en la primera crónica del Diario firmada «Jo-valle», se aumenta el tono desolado con tintes que el autor vitupera en otros escritores:

na». Diario de Reus, 6-3-1868, año X, $\mathrm{n}^{\circ} 54$ [n 55], pp. 1-2, y «Crónica de París». El Imparcial, 6-3-1868, año II, $\mathrm{n}^{\circ} 309$, s. p., datadas el 29 de febrero, y las revistas con fecha del 9 y el 17 de marzo citadas. No he localizado estos artículos en otros diarios de Madrid en que colaboró Vallejo. A parte de la bibliografía sobre él ya mencionada, véanse SINCLAIR, Alison. Madrid Newspapers. 1661-1870. A computerized handbook based on the work of Eugenio Hartzenbusch. Leeds, W. S. Maney and Son, 1984, p. 759, y Veinticuatro diarios (Madrid, 1830-1900). Artículos y noticias de escritores españoles del siglo XIX, t. IV. Madrid: CSIC, 1975, p. 439.

${ }^{18}$ Anecdóticamente, en la versión del Diario de la revista datada el 17 de marzo, se elogia a la soprano Cristina Nilsson, futura esposa de Vallejo, con quien se casará en 1887, como precisan varias biografías de ella.

${ }^{19}$ PICO DE LA MIRÁNDOLA. «Cartas parisienses». La Ilustración Española y Americana, 19 de marzo, 22-3-1877, año XXI, n 11, p. 190; DAVIS, G. «The Critical Reception of Naturalism in Spain before La cuestión palpitante», pp. 97-98, da noticia ya de este artículo y de otros con el mismo pseudónimo comprendidos entre 1876 y 1877 . Los de esta revista se citan también en otros estudios.

${ }^{20}$ PICO DE LA MIRÁNDOLA. «Cartas parisienses», 12 de abril. La Ilustración Española y Americana, 15-4-1877, año XXI, ${ }^{\circ}$ 14, p. 251. PATTISON, W. T. El naturalismo español, p. 13, conjetura que este artículo prueba que Vallejo no tenía «una idea clara de lo que era el naturalismo, en que incluye la poesía de Béranger», pero la referencia aducida no corresponde a Les gueux, de este poeta, sino a «Les chansons des g[u]eux», de Richepin.

${ }^{21}$ PICO DE LA MIRÁNDOLA. «Crónica parisiense». La Ilustración Española y Americana, 8-12-1888, año XXIX, no 45 , p. 338.

${ }^{22} \mathrm{Me}$ he referido a ello en «Pompeu Gener, un positivista darwinista contrario al naturalismo zoliano (colaboraciones en la prensa de Barcelona y Madrid)». Revista de Filología Románica, 2008, vol. XXV, pp. 313-335. 
En las calles, una espesa capa de nieve fétida, mezcla inenarrable de todos los detritus parisienses, combinados con el agua congelada del cielo; en la atmósfera, una niebla espesa cargada de miasmas repugnantes; en los salones públicos y privados, un público soñoliento, impresionado en su modo de ser moral por estas detestables condiciones climatéricas ${ }^{23}$.

El teatro está también aletargado y el único «libro de nota» es La comtesse de Châlis, de Ernest-Aimé Feydeau. No duda en atribuir «esta escasez»al hecho de que «gran parte de los ingenios que podrían cultivar con éxito y aún con gloria» la novela «han sido absorbidos por el periodismo, que da en este país honra y provecho. ¡Dígase luego que no hay Pirineos!» ${ }^{24}$. En la crónica cultural siguiente, volverá a considerar la actividad teatral muy poco reseñable y a envidiar, a raíz del homenaje a Molière, el reconocimiento del escritor en Francia ${ }^{25}$.

La «revista de la semana» posterior no lleva firma, pero, como veremos, «Ángel Jo-valle» se la atribuye en otra ${ }^{26}$. Tras resaltar la dificultad de efectuar la «disección» de un intervalo más repleto «de accidentes y movimientos que un tomo de [...] Ponson du Terrail», el creador del personaje del que procede el adjetivo «rocambolesco», y lamentar que el oficio de «gacetillero» reduce la «inteligencia» «a la ingrata tarea de redactor de sumarios», recomienda que, en lugar de las desafortunadas versiones de obras francesas que se representan en los escenarios hispánicos, se adapte la comedia Paul Forestier, de Émile Augier, «uno de los pocos autores que honran la literatura dramática del día en Francia».

Interpreta que la «ovación» de los espectadores y de la crítica a esta obra supone «una protesta contra la literatura que reina, la cual en el teatro no ofrece sino sandeces salpicadas de obscenidades y en la novela ha creado una escuela monstruosa que va más allá, esto es, que trata de excitar el paladar gastado del público con la poesía de los anfiteatros quirúrgicos y con los miasmas de putridez, viendo que ya no basta para satisfacerlo el solo atractivo de la desnudez»:

Los últimos libros que las prensas parisienses han ofrecido al público en este ramo literario pertenecen a semejante género degradado. Germinia Lacerteux [(1865),

\footnotetext{
${ }^{23}$ Revista fechada el 14 de enero ya citada.

${ }^{24}$ Resalta también, como una de las «paradojas de la Babilonia moderna», que, «en contradicción con el pretendido ateísmo de París», los sermones, «llenos de elocuencia», atraen más público del que cabe en la catedral. Insistirá en la religiosidad de los franceses en JOVALLE, Ángel. «Revista de la semana», 12 de abril. Diario de Reus, 16-4-1868, año X, $\mathrm{n}^{\circ}$ 87 [ ${ }^{\circ} 88$ ], pp. 1-2, aunque dejará a otros «talentos más capaces» la responsabilidad de «hacer triunfar los sublimes principios del cristianismo sobre el racionalismo».

25 JO-VALLE, Á. «Revista de la semana. (De nuestro corresponsal)», 21 de enero. Diario de Reus, 25-1-1868, año $\mathrm{X}, \mathrm{n}^{\circ} 20$, p. 1.

${ }^{26}$ «Revista de la semana. (De nuestro corresponsal)». Diario de Reus, 7-2-1868, año X, $\mathrm{n}^{\circ} 31$, p. $1-2$.
} 
de Edmond y Jules Goncourt], Teresa Raquin y la misma Condesa de Châlis son obras que debieran figurar más bien en la biblioteca de un cirujano, como estudio de ciertos desórdenes físicos a que está sujeta la naturaleza humana en los grandes centros de la depravación, que no sobre la mesa de los salones en que se hace gala de seguir con interés el movimiento literario de la época.

Respetamos demasiado a nuestros lectores para desmenuzar semejantes horrores, de que debemos dar cuenta, no obstante, como signo del tiempo en esta sociedad y porque son la novedad del día; pero, para justificar nuestra apreciación y repugnancia, diremos dos palabras sobre el asunto que desenvuelve una de estas novelas, Teresa Raquin.

Redúcese este tomo a la pintura del remordimiento físico de dos amantes que matan a un marido para entregarse con más libertad al adulterio, pero que, una vez que han ejecutado su crimen, no aciertan a abrazarse porque sienten entre sus carnes el cuerpo del difunto a quien ahogaron, el cual creen estrechar, putrefacto y viscoso, interpuesto entre sus caricias. $=i P u u h !=$

Apartemos la vista de esta literatura de hospital que el Imperio tiene la triste gloria de haber engendrado.

Estas críticas parecen inspirarse en el artículo que, a finales del mes anterior, había publicado «Ferragus» (Louis Ulbach), con el título de «La littérature putride», la cual ejemplificaba con las mismas novelas:

Il s'est établi depuis quelques années une école monstrueuse de romanciers, qui prétend substituer l'éloquence du charnier à l'éloquence de la chair, qui fait appel aux curiosités les plus chirurgicales, qui groupe les pestiférés pour nous en faire admirer les marbrures, qui s'inspire directement du choléra, son maître, et qui fait jaillir le pus de la conscience. [...]

Germinie Lacerteux, Thérèse Raquin, La comtesse de Châlis, bien d'autres romans qui ne valent pas l'honneur d'être nommés (car je ne me dissimule pas que je fais une réclame à ceux-ci) vont prouver ce que j'avance. [...]

C'est de la chirurgie; et si une fois par hasard un écorché peut être indispensable à la démonstration psychologique, l'écorché mis en système n'est plus que de la folie et de la dépravation ${ }^{27}$.

\section{Además, Ulbach sintetizaba similarmente Thérèse Raquin:}

Le sujet est simple, d'ailleurs, le remords physique de deux amants qui tuent le mari pour être plus libres de le tromper, mais qui, ce mari tué (il s'appelait Camille), n'osent plus s'étreindre, car voici, selon l'auteur, le supplice délicat qui les attend: "Ils poussèrent un cri et se pressèrent davantage afin de ne pas laisser entre leur chair de place pour le noyé. Et ils sentaient toujours des lambeaux de Camille qui s'écrasaient ignoblement entre eux, glaçant leur peau par endroits, tandis que le reste de leur corps brûlait.».

Zola le respondió alegando, entre otros argumentos:

${ }^{27}$ FERRAGUS. «Lettres de Ferragus. III. La littérature putride». Le Figaro, 23-1-1868, año XV, $\mathrm{n}^{\circ}$ 23, p. 1. Artículo recopilado en ZOLA, É. Euvres complètes, t. I, pp. 673-676. En PICO DE LA MIRÁNDOLA. «Cartas del lunes», 15 de marzo. El Imparcial, 21-3-1876, año X, no 3168 , se elogiará Magda, de Ulbach. 
Vous restez à fleur de peau, monsieur, tandis que les romanciers analystes ne craignent pas de pénétrer dans les chairs. C'est moins voluptueux, et moins agréable, je le sais; les tableaux vivants, les apothéoses de féerie sont excellents pour procurer des rêves amoureux: la vue d'une salle d'amphithéâtre est au contraire écœurante pour ceux qui n'ont pas l'amour austère de la véritée ${ }^{8}$.

La contrarréplica de Ulbach se publicó el 6 de febrero, por lo que no podía tenerla en cuenta la crónica del Diario, editada al día siguiente.

Entre las «revistas» posteriores, destaca una que, además de bromear sobre la mayor familiaridad «con las elucubraciones de Stuar[t]-Mill, Laboulaye y Mo[n]talembert que con las confecciones de Worth (el sastre de las damas a la moda)», salva de «la falta de novedades teatrales y editoriales», Cahier bleu de Mlle. Cibot, de Gustave Droz, que contrapone a Thérèse Raquin:

El asunto de la novela es semejante al de Teresa Raquin, que analizamos en una de nuestras últimas revistas. Trátase, en esta como en aquella, de una joven de temperamento ardiente, ansiosa de pasión y que casa con un marido enfermizo e impotente. La señorita Cibot no ahoga a su marido, como Teresa, pero lo mata a disgustos, como se dice vulgarmente, para entregarse con más libertad a su amante y, una vez libre, su conciencia sobresaltada, lejos de permitir gozar de la independencia conquistada con un crimen moral, la precipita en la desesperación y en el suicidio.

Esta tesis atrevidísima, que ahora está de moda, tiene al menos la ventaja, en el libro de Mr. Droz, de estar desarrollada con reserva y de modo que la honestidad del lector no sufra de las pinturas a que tan escabroso asunto se presta. En una palabra: el libro, si audaz en el asunto, es moderado y sano en la forma y sumamente moral en sus deducciones y desenlace, el cual muestra lo incompatible de la felicidad con una conciencia turbada por el remordimiento. A falta, pues, de otra obra más meritoria, recomendamos la lectura del Cuaderno azul de la señorita Cibot, que es la novedad del momento y que no carece de dotes de estilo y de otras cualidades literarias ${ }^{29}$.

El corresponsal del Diario, a pesar de coordinar «realismo» con «indiscreciones» a propósito del teatro, no tiene ningún reparo a continuación en dar detalles escabrosos de un envenenamiento, del que culpa a un médico, lo que le permite sentenciar que «la peor enfermedad que aqueja a la humanidad es la medicina $»^{30}$. o parece que lo haga solamente para bromear con la paradoja, dado que, a pesar de ser absueltos todos los acusados, insiste en que, «si

${ }^{28}$ ZOLA, Émile. «Lettre à Ferragus». Le Figaro, 31-1-1868, año XV, no 31, p. 2. Reproducida en ZOLA, É. CEuvres complètes, t. I, pp. 677-680.

${ }^{29}$ JO-VALLE, Ángel. «Revista de París», 22 de febrero. Diario de Reus, 27-2-1868, año $X, n^{\circ} 47\left[n^{\circ} 48\right]$, pp. 1-2.

${ }^{30}$ Revista datada el 17 de marzo. Con esta misma fecha y en el mismo día, se publica en el Diario una correspondencia anónima parisiense en que se aboga por no dar «los honores de la represión legislativa y ministerial» a una tesis de medicina presentada en París que defiende el determinismo (21-3-1868, año $X, n^{\circ} 67$ [nº 68], p. 2). 
hay alguno de quien pueda sospecharse que administró el veneno», es el «bárbaro matachín», sobre el que vierte todo tipo de infundadas acusaciones ${ }^{31}$.

En cambio, se muestra elogioso con otros campos científicos e incluso se propone dedicar una parte de las crónicas a la ciencia, dado que «el deber de la prensa es hacer notar los nombres de estos apóstoles del progreso científico» ${ }^{32}$. En cualquier caso, ilustrará especialmente las limitaciones de la actitud de Vallejo hacia la ciencia y, en concreto, hacia Bernard un artículo en que caricaturiza que, con sus experimentos sobre la sensibilidad vegetal, yendo más allá de Littré y de Darwin, asimila al hombre «con la alfalfa», «las coles y los cardos borriqueros $»^{33}$.

\section{EL PRINCIPADO}

El corresponsal en París de este diario, Josep Coroleu, si bien había editado un poemario todavía en buena parte romántico, Cants de la naturalesa, en cuyo prólogo (fechado en París el 11 de abril de 1866) resaltaba que no lo podrían tildar ni de inmoral ni de reaccionario, será uno de los introductores del positivismo en la historiografía ${ }^{34}$.

En 1867, además de hacer la necrología de Baudelaire, al que consideraba «exageradamente realista», se lamentaba de que, muerto Balzac, no había aparecido nadie capaz de «trazar» la «fisonomía» de París «con entera exactitud» ${ }^{35}$. Más en general, daba por casi extinguida «la generación

${ }^{31}$ JO-VALLE, Ángel. «Revista de la semana», 25 de marzo. Diario de Reus, 31-3-1868, año $X, n^{\circ} 74$, pp. $1-2$.

32 JO-VALLE, Ángel. «Revista de la semana». 3 de abril, Diario de Reus, 7-4-1868, año $\mathrm{X}, \mathrm{n}^{\circ} 80\left[\mathrm{n}^{\circ} 81\right]$, p. 1 .

${ }^{33}$ PICO DE LA MIRÁNDOLA. «Cartas del lunes». 30 de agosto, El Imparcial, 4-9-1876, año $X, n^{\circ} 3332$, p. 4. Letamendi, en su célebre discurso de 1867 en el Ateneo Catalán, ya había acusado al transformismo de convertir al hombre en «nieto de una col». (Obras completas. Madrid: Rodríguez Ojeda, 1907, p. 216).

${ }^{34}$ COROLEU, J. Cants de la naturalesa. Himnes $i$ rondalles. Escrits en vers català. Barcelona: Verdaguer, 1866. Véanse CATTINI, Giovanni C. Historiografia i catalanisme. Josep Coroleu i Inglada (1839-1895). Catarroja / Barcelona: Afers, 2007; TORRENT, Joan; TASIS, Rafael. «Un diari que canvia sovint de nom: El Telégrafo». En: id. Història de la premsa catalana, t. I. Barcelona: Bruguera, 1966, pp. 116-122; 200 anys de premsa diària a Catalunya. Josep Maria Huertas (dir.). Barcelona: Arxiu Històric de la Ciutat / Col-legi de Periodistes / Fundació Caixa de Catalunya, 1995, pp. 128-129; GHANIME, Albert. Joan Cortada. Catalunya $i$ els catalans al segle XIX. Barcelona: Abadia de Montserrat, 1995. Aunque las crónicas de Coroleu para este diario eran ya conocidas, no me consta que se hayan mencionado los aspectos que comentaré.

${ }^{35}$ Respectivamente, C., J. «París, 3 de septiembre». El Principado, 6-9-1867, n 249, pp. 4876-4877, cuya referencia a Baudelaire se añade a las aducidas por la bibliografía sobre su recepción, y COROLEU, J. «Revista de París». El Principado, 15-9-1867, pp. 6086-6087, $\mathrm{n}^{\circ}$ 258, y Diario de Reus, 17-9-1867, año IX, n 219, p. 1. En C., J. «Revista de París». El Principado, 1-7-1868, $\mathrm{n}^{\circ}$ 180, pp. 4158-4159, se destacará a Balzac como creador del «tipo inmortal» de «»el grande hombre de provincia en París»». 
de $1830 »$ y consideraba su sucesora «bien raquítica y mezquina comparada con ella ${ }^{36}$.

Sin embargo, a inicios de 1868, antes que el cronista del Diario de Reus y con otros criterios, detecta cierta recuperación cultural: París, cansado «de leer obras frívolas, de oír música trivial, de contemplar espectáculos insulsos», «empieza a romper despiadadamente sus ídolos de ayer» ${ }^{37}$. Entre otras obras, lo prueba La comtesse de Châlis, «pintura genial de las costumbres contemporáneas, sátira vigorosa y desapiadada, cuyos viriles acentos, cuya indignación sincera y vehemente han hecho honda mella en los ánimos», si bien «algunos espíritus descontentadizos censuran, con pérfida blandura, el marcado realismo de esta obra, recordando, como de paso, que el autor pagó su tributo al sensualismo de la época en las apasionadas escenas de Fanny» ${ }^{38}$. Coroleu defiende el carácter regenerador del realismo, comparándolo con la medicina:

Ni el médico cura la gangrena con paliativos ni el moralista corrige los vicios con idilios. Feydeau conoce bien la sociedad en que vive y no quiere velarle los males que la llevan fatalmente a la decadencia. Por esto, su pluma inexorable, como el escalpelo del cirujano, analiza las llagas sociales con una intrepidez que la superficialidad y el egoísmo tachan de estudiada crueldad. Los hombres son como la vieja de la fábula: no les agrada la fidelidad del espejo.

Como hemos visto, Ulbach se había referido a esta novela unos días antes en Le Figaro. Coroleu define este diario como la «gaceta de la sociedad elegante», lo destaca como el parisino que está «más al corriente de las noticias literarias» y sabe que el pseudónimo de «Ferragus» «vela un nombre ilustre», sin precisar de quién se trata, aunque todo ello no implica que leyera la reseña ${ }^{39}$.

Coroleu, unos meses después de su defensa en término médicos del realismo de La comtesse de Châlis, a propósito del debate en el senado francés sobre las pretendidas «tendencias materialistas» de algunas facultades de medicina, argumenta que la École de Médicine de Paris sigue el «método

${ }^{36}$ COROLEU, J. «Revista de París». El Principado, 15-10-1867, nº 283, pp. 6786-6788.

${ }^{37}$ C., J. «Revista de París», 5 de enero. El Principado, 10-1-1868, nº 9, pp. 180-181.

${ }^{38}$ C., J. «Revista de París». El Principado, 28-1-1868, n 27, pp. 613-614. Entre los que habían criticado a Feydeau, se encuentran Alarcón y Valera (DAVIS, Gifford. «The Spanish Debate over Idealism an Realism before the Impact of Zola's Naturalism», PMLA, octubre 1969, vol. LXXXIV, nº 6, p. 1649; LÓPEZ JIMÉNEZ, Luis. El naturalismo y España. Valera frente a Zola. Madrid: Alhambra, 1977, p. 36; CAUDET, Francisco. «La querella naturalista. España contra Francia». En: Realismo y naturalismo en España en la segunda mitad del siglo XIX. Barcelona: Anthropos, 1988, pp. 59-60, 70-71; SOTELO VÁZQUEZ, Adolfo. El naturalismo en España: crítica y novela. Salamanca: Almar, 2002, pp. 56-59).

${ }^{39}$ Respectivamente, «Revista de París. La prensa literaria». El Principado, 1-12-1867, no 335, pp. 7862-7864; C., J. «Correspondencia», 12 de agosto, El Principado, 15-8-1868, $\mathrm{n}^{\circ}$ 224, pp. 5193-5194, y C., J. «Correspondencia», 27 de agosto, El Principado, 30-8-1868, $\mathrm{n}^{\mathrm{o}} 238$, pp. 5514-5515. 
experimental porque a él se deben los grandes progresos que ha hecho la ciencia en nuestro siglo», renunciando a «cuestiones metafísicas», entre las que sitúa también el materialismo, que niega defender, si bien se queja de se anatematice conociéndolo solamente de oídas ${ }^{40}$.

Abunda en ello en un panorama filosófico ${ }^{41}$. Precisa que el positivismo, escudándose en la actitud antimetafísica y prescindiendo de las «causas primeras», ha procurado mantenerse alejado tanto del espiritualismo como del materialismo, pero, dada la tentación y «difícil neutralidad», «no pocos materialistas» son «ardientes sectarios del positivismo» $\mathrm{y}$ «muchos positivistas» «profesan el materialismo sin echarlo de ver». De este modo, el «positivismo ha sido un período de transición, una escuela fugaz, que sólo ha servido para preparar el terreno al materialismo». Este, que cuenta con precedentes remotos (como los atomistas y epicúreos) y se ha enriquecido con «nociones científicas», «no solo prescinde de la divinidad, sino que la niega; no se contenta con suprimir la metafísica, sino que además usurpa su puesto», salvando algunas objeciones, «con suma destreza», al vincular la «fuerza» a la «materia». Se trata de una «teoría, rigurosamente lógica — admitida la base de su argumentación-», que «no podía menos de seducir, cautivar y arrastrar los ánimos, cansados de las cavilaciones panteístas y de los delirios del idealismo». Sin embargo, considera que «M. [Elme-Marie] Caro ha puesto el dedo en la llaga» al sentenciar: «Dejadla pasar: hoy es moda ser materialista»» ${ }^{42}$.

El «método experimental», que «no es más que un auxiliar de la ciencia y «excluye todo propósito deliberado de convertir a la ciencia en aliada de un sistema filosófico determinado». «El gran fisiólogo Claudio Bernard, a cuya iniciativa tanto debe la ciencia médica», concibió el positivismo como Stuart Mill, «a quien los discípulos de Comte arrojaron de sus filas por heterodoxo». Coincidiendo implícitamente con Bernard, Coroleu considera que la observación lleva a «inducciones conducentes al principio del «determinismo universal»», que solo puede ser tildado de «fatalismo» por «los espíritus superficiales», ya que es «su antítesis» (mientras el supersticioso cree que el hombre muerto por un rayo estaba predestinado, «el determinista estudiará el hecho y las circunstancias que lo acompañaron, llegando por este estudio al conoci-

${ }^{40}$ C., J. «Correspondencia», 25 de mayo. El Principado, 28-5-1868, ${ }^{\circ}$ 147, pp. 33993400. Ya había lamentado el desconocimiento de esta tendencia por los espiritualistas, pero dejando claro que no era, «ni mucho menos», materialista (C., J. «Revista de París». El Principado, 19-4-1868, $\mathrm{n}^{\circ}$ 108, pp. 2505-2506).

${ }^{41}$ C., J. «Revista de París». El Principado, 7-6-1868, no 157, pp. 3632-3634, e, id. «La filosofía en Francia». El Principado, 14-6-1868, n 164, pp. 3794-3795, que pudieron inspirarse, entre otras posibles fuentes, en RAVAISSON, Félix. La philosophie en France au 19ème siècle. Paris: Hachette, 1867.

${ }^{42}$ Joaquim Riera i Bertran evoca que en 1868 asistió a las lecciones de Caro relativas al positivismo en la Sorbona (R., «Lo llenguatge. I». La Renaixensa, 27-5-1885, año XV, ${ }^{\circ}$ 2671, p. 3067; DURAN, Carola. «Propostes de modernització del teatre català des de $L a$ Renaixensa (1871-1905)». Assaig de Teatre, 2004, $\mathrm{n}^{\circ}$ 41, p. 158). 
miento de una ley natural»). «El determinismo analiza los hechos partiendo del principio inducto de que, en condiciones idénticas, todo fenómeno es idéntico», lejos de pretender, «como el positivismo, que el hombre deba ceñirse a la observación de lo real»o, «como el materialismo, negar las causas primeras». «Sus pretensiones son más modestas, son puramente prácticas; y, sin embargo, la humanidad le debe inmensos servicios».

Concluye que «en la prensa y en el senado se ha tildado recientemente de materialistas a los sabios eminentes que profesaban este método; pero los que tal dijeron no entienden de materialismo, de determinismo ni de filosofía», e ironiza con la anécdota de «un ilustre profesor de la Escuela de Medicina» de París que, preguntándole porque «no hacía nunca mención del alma en sus lecciones», replicó que hablaría de ella cuando la encontrase «con el escalpelo», obviedad que ha sido atribuida también a otros médicos ${ }^{43}$.

Sería interesante conocer la opinión sobre Thérèse Raquin de un buen conocedor del método experimental, el determinismo, el positivismo y el materialismo y defensor del realismo. Sin embargo, he localizado solamente una mención suya de 1868 a «el crítico Émile Zola», entre otros redactores de La Tribune que prueban que este periódico se alinea en «la oposición radical» ${ }^{44}$. Considera que los artículos de este diario son los «más atrevidos y contundentes» que recuerda haber leído en París y subraya que, sin ser «violento», «es cáustico y toca las cuestiones con aquella habilidad que sólo se adquiere por medio del estudio y de la meditación».

Poco después, proclamará: «La preponderancia del periodismo significa que, en una época como la nuestra, la literatura debe ser, por fuerza, militante» ${ }^{45}$. Producido el «glorioso alzamiento» de la Revolución de Septiembre, incitará a abandonar la indiferencia y a participar en las elecciones y, más en general, en «»la cosa pública»», que «se llama así porque a todos interesa» ${ }^{46}$. Coincide, pues, con Zola también en el compromiso cívico del escritor.

Justamente en una conferencia sobre la función social del artista, unos veinte años después, considerará que los naturalistas, «para protestar del convencionalismo que no reza en la naturaleza sino lo superlativamente bello,

${ }^{43}$ C., J. «Correspondencia», 27 de mayo. El Principado, 30-5-1868, no 149, p. 3448, informa del agradecimiento de los estudiantes de medicina al senador y crítico literario SainteBeuve por su oposición a la intervención del Estado en tales asuntos. Véase también BUTLER, R. «Zola between Taine and Sainte-Beuve 1863-1869». Modern Language Review, abril 1974, vol. LXIX, n 2, pp. 279-289.

${ }^{44}$ C., J. «Correspondencia», 15 de junio. El Principado, 18-6-1868, n 168, pp. $3877-$ 3878. El término «crítico» parece usarse en el sentido literario, dado que Zola era ya conocido en esta faceta y el carácter contestatario de la publicación se resalta en conjunto. C., J. «Correspondencia», 12 de junio. El Principado, 15-6-1868, n 165, p. 3816, había anunciado la publicación de este «periódico político semanal, dirigido por los célebres diputados de la oposición M. M. Pelletan y Glais Bizoin», sin mencionar todavía a Zola.

${ }^{45}$ C., J. «Revista de París». El Principado, 27-7-1868, n 205, pp. 4751-4752.

${ }^{46}$ COROLEU, J. «Los indiferentes». El Telégrafo, 5-10-1868, año IX, nº 6, pp. 116-118. 
cayeron en el extremo de no mirar sino lo superlativamente feo»y abogará por representar, «con buen sentido» $\mathrm{y}$ «buen gusto», «la naturaleza» no «idealizada», sino «calaminada», es decir, plasmada en la escritura ${ }^{47}$.

\section{CONCLUSIÓN}

Aunque es posible que se localicen otras referencias a Zola anteriores o que las citadas se reproduzcan en más periódicos, estas remontan ya la recepción hispánica al inicio de la proyección más significativa de este escritor, en dos facetas: como autor de Thérèse Raquin (a la que las crónicas publicadas el 7 y el 27 de febrero de 1868 en el Diario de Reus, escritas muy probablemente por Ángel Vallejo Miranda, reprochan el componente médico y el carácter pretendidamente depravado) y como «crítico» cuya participación en la redacción de La Tribune prueba la ideología antigubernamental del periódico (en una gacetilla de Josep Coroleu editada en El Principado el 18 de julio).

Si bien la propuesta literaria de Zola todavía no se había desarrollado ni proyectado plenamente y su incidencia se intensificará a mediados de los setenta y será más plena en los ochenta, las actitudes de estos corresponsales manifiestan ya dos tendencias contrapuestas respecto al trasfondo ideológico del naturalismo zoliano, que presentarán una amplia gama de matices.

Este estudio muestra también, además de la circulación de información sobre diversos ámbitos de la vida parisina, la presencia del materialismo, el positivismo y la medicina experimental en la prensa hispánica ya antes de la Revolución de Septiembre de 1868, considerada un hito en su difusión.

Fecha de recepción: 18 de marzo de 2009

Fecha de aceptación: 15 de octubre de 2009

${ }^{47}$ «De la misión del artista». La Vanguardia, 4-3-1888, año VIII, n ${ }^{\circ} 106$, pp. 1-2. 